\title{
Content and quality of website information on the treatment of oral ulcers
}

IN BRIEF
Presents information regarding the
content, quality and type of web-based
information for the treatment of oral
ulceration.
- Explores the need for the clinician to
provide direction to patients searching
online for health information due to
the questionable quality of some of the
information available.
Discusses shared decision-making in
healthcare.
healthcare.

\author{
R. Ni Riordain*1 and T. Hodgson ${ }^{1}$
}

\begin{abstract}
Aims and objective To determine the type, accuracy and content of information available on the Internet regarding the treatment of oral ulcers. Method The search engine Google was used to generate a list of top 100 websites about 'mouth ulcer treatment'. The websites were evaluated using the DISCERN instrument and the JAMA benchmarks. Whether the site displayed the Health on the Net (HON) seal was also recorded. Results The search yielded 1,460,000 sites on the Google website. Of the top 100 sites a total of 54 sites were suitable for analysis due to duplicate links and non-functioning links. Of the websites analysed, 31.5\% achieved all four JAMA benchmarks and 13\% achieved only one benchmark. No website receiving the maximum mark on the overall score and six websites received the lowest overall score regarding the DISCERN instrument. The questions with the poorest response score were 'Does it describe how the treatment choices affect overall quality of life?' and 'Does it provide support for shared decision-making?'. Only 7.4\% of the websites displayed the HON seal. Conclusion Diverse information regarding the treatment of oral ulcers is available on the Internet with variable accuracy levels based on both JAMA benchmarks and DISCERN.
\end{abstract}

\section{INTRODUCTION}

An oral ulcer is defined as 'a break in the mucosal surface of the oral cavity.' ${ }^{1}$ They are common and can be due to local factors such as trauma from dentures or fractured dentition or a vast number of systemic diseases can manifest as ulcerations in the oral cavity. ${ }^{2}$ Recurrent aphthous stomatitis (RAS) is the most common form of oral ulceration that affects up to $25 \%$ of the worldwide population..$^{3-5}$ RAS presents as recurring, round or ovoid painful ulcers surrounded by erythematous haloes and grey/yellow bases. They are considered to be one of the most painful oral mucosal inflammatory conditions and can cause discomfort with eating, swallowing and speaking. ${ }^{6}$ Treatment for RAS is not curative and management is aimed at symptomatic relief. As with other oral ulcerative conditions, the chronic nature of RAS, the symptomatic manifestations and the possible side effects of the medication used to provide symptomatic relief can have an effect on the daily life of patients.

'UCLH NHS Foundation Trust, Eastman Dental Hospital, UCL Eastman Dental Institute, 256 Grays Inn Road, London, WC1X 8LD

${ }^{*}$ Correspondence to: Dr Richeal Ni Riordain

Email: richeal.niriordain@gmail.com

Online article number E15

Refereed Paper - accepted 22 July 2014

DOI: 10.1038/sj.bdj.2014.886

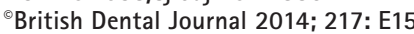

Information regarding health problems is one of the most commonly researched topics on the Internet. ${ }^{7}$ According to a recent survey of the US population $80 \%$ of Internet-using adults search the web for health-related information, ${ }^{8}$ with $70 \%$ of those surveyed stating that the information gathered influenced the treatment of their condition or illness. This web information collated by patients is not generally seen as replacing advice given by healthcare professionals but as confirmation and supplementation of the information they provide. ${ }^{9}$ Not only is information about their healthcare problems available but support and advice from both professionals and fellow patients can also be accessed. ${ }^{10}$

Although web-based information is largely trusted,,$^{11}$ the quality of health information available on the Internet has been called into question. ${ }^{12}$ The quality of Internet information regarding some orofacial conditions has been assessed in the recent past. ${ }^{13,14}$ We could, however, find no such publication regarding the content or quality of online information on the treatment of oral ulcers. The aim of this study is to determine the type, accuracy and content of information available on the Internet regarding the treatment of oral ulcers.

\section{MATERIALS AND METHODS}

The search term 'mouth ulcer treatment' was used on the Google search engine for all the responses on 1 December 2012. We then examined the first 100 sites listed. A proforma was used to collect the following data: site affiliation (commercial, nonprofit organisation, government, university/ medical centre), content type (medical facts, clinical trials, human interest stories, question and answer), DISCERN score, the Journal of the American Medical Association (JAMA) benchmarks for website analysis score and the presence of the Health on the Net (HON) seal.

DISCERN is a valid and reliable 16-point questionnaire, the aim of which is to aid health consumers and information providers to evaluate the quality of information about treatment choices for health problems. ${ }^{15}$ The JAMA benchmarks demand that a website should display authorship of medical content (authors and contributors, their affiliations and relevant credentials), source (references and attribution of information), disclosure (website ownership, conflicts of interest) and currency (dates content posted and updated). ${ }^{16}$ Established in 1995, Health on the Net is a non-profit foundation to guide both the general public and medical professionals to reliable sources of health information on the Internet. The HON seal is awarded to websites that uphold the HON code of conduct, ${ }^{17}$ which consists of eight elements, including the qualifications of the authors to clearly distinguish advertising from editorial content. 


\begin{tabular}{l|l}
$\begin{array}{l}\text { Table } 1 \text { Categorisation of websites based } \\
\text { on affiliation and content type } \\
\text { Categorisation }\end{array}$ & Number \\
\hline Affiliation & 33 \\
\hline Commercial & 14 \\
\hline Non-profit organisation & 2 \\
\hline University or medical centre & 5 \\
\hline Government & \\
\hline Content type & 47 \\
\hline Medical facts & 32 \\
\hline Clinical trials & 9 \\
\hline Question and answer & 13 \\
\hline Human interest stories &
\end{tabular}

Table 2 Website content based on JAMA benchmarks

\begin{tabular}{l|l}
\hline JAMA benchmarks & Number \\
\hline Authorship & 15 \\
\hline Attribution & 18 \\
\hline Disclosure & 31 \\
\hline Currency & 33 \\
\hline
\end{tabular}

\section{RESULTS}

The search yielded $1,460,000$ sites on the Google website. Of the first 100 sites, 44 represented duplicate links and two were non-functioning links. A total of 54 sites remained for analysis.

Table 1 represents the categorisation of the 54 websites analysed showing a majority $(61 \%)$ of these sites were commercial.

Table 2 represents the results of the JAMA benchmarks. Seventeen websites achieved all four benchmarks while only seven websites achieved only one benchmark.

Four of the 54 websites analysed displayed the HON seal.

Figure 1 represents the distribution of the overall scores achieved by websites using the DISCERN instrument with no website receiving the maximum mark on the overall score and six websites received the lowest overall score. The questions with the poorest response scores were 'Does it describe how the treatment choices affect overall quality of life?' and 'Does it provide support for shared decision-making?'.

\section{DISCUSSION}

The impact of the Worldwide Web in providing healthcare information and consequently on the health of the patient cannot be underestimated, with a wellinformed patient more likely to have better compliance and outcomes. ${ }^{18}$ The evolving

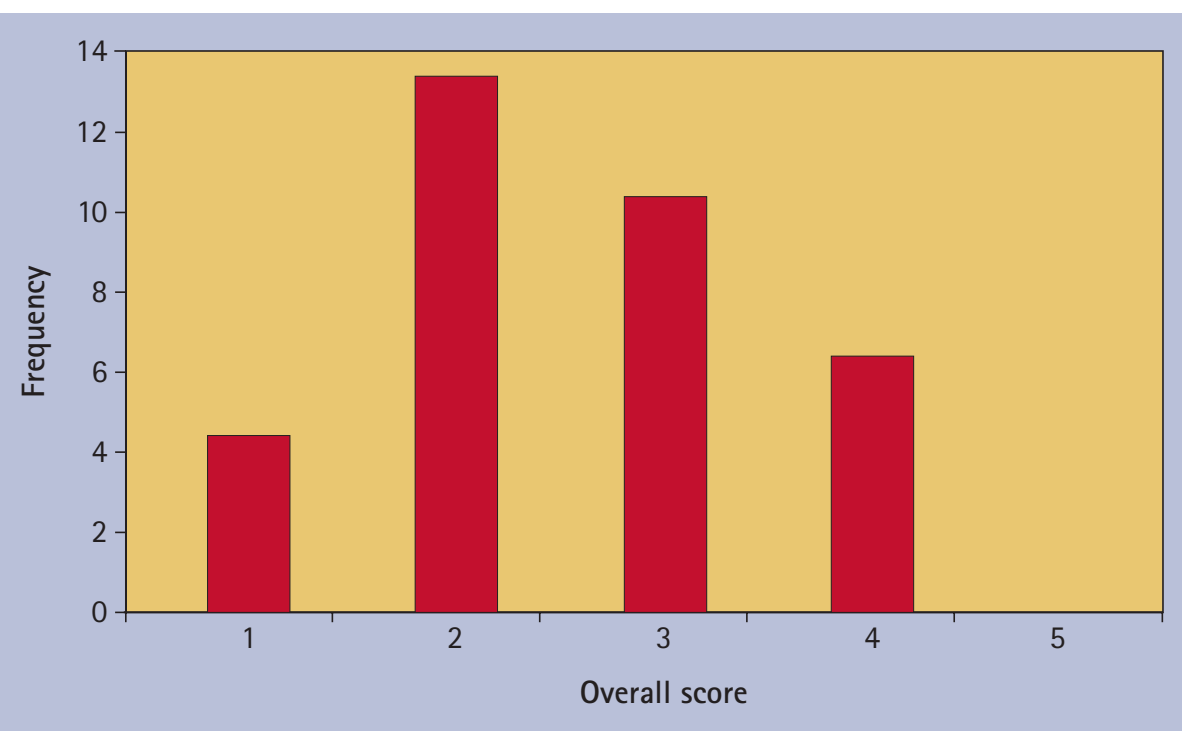

Fig. 1 Frequency distribution of overall scores achieved by websites using the DISCERN instrument

doctor-patient relationship, which is allowing for greater shared decision-making and encouraging patients who are interested and informed to take a more active role in the management of their health, can also be somewhat attributed to the increased accessibility of health information. ${ }^{19}$ However, in spite of the obvious benefits of web-based health information, concerns also exist, due principally to the skill level required to accurately interpret the acquired medical-based information. Without this skill a patient be may be unable to identify biased content or may fail to recognise that critical information is missing. ${ }^{20}$ They may be unable to recognise non-evidence-based material and even misunderstand some of the medical information provided. ${ }^{21}$ These concerns regarding biased content and poorly referenced non-evidenced based material is well founded, based upon the poor scores in the following DISCERN questions: 'Is it clear what sources of information were used to compile the publication?' and 'Is it balanced and unbiased?', in this study. It has been suggested the responsibility lies with healthcare professionals to address these concerns and to teach patients how to analyse or filter information. ${ }^{22}$

'Marmite'23 and 'beer rinses'24 were just two of the vast array of treatment options presented when searching online regarding the treatment of oral ulcers. Needless to say the quality of scientific data to support these particular treatments were nonexistent, however, would the general public be able to filter the Internet information and deduce safer more evidence-based options for treatment? Although there has been government lead initiatives to promote science among the public ${ }^{25}$ it is also important to acknowledge that one in six of the UK population have literacy difficulties, ${ }^{26}$ so are we as healthcare professionals providing sufficient support for patients in seeking information on health problems? When specifically considering oral health literacy (OHL), recent studies have found an association between levels of OHL and oral health-related quality of life and oral health status. ${ }^{27,28}$ In a review published by The Cochrane Collaboration regarding communication with patients about evidence-based medical information the authors found that irrespective of the format, be it leaflet or video, information provided to patients increased their understanding of the evidence. ${ }^{29}$ Only one of the websites reviewed in this study presented information regard the treatment of oral ulcers in video format. Previous studies have demonstrated that information provided by video clips has increased patient knowledge and reduced anxiety levels. ${ }^{30,31}$ Perhaps the information leaflets commonly distributed by healthcare practitioners could provide a link to a video clip, thereby facilitating patients of all literacy levels, leading to more widespread engagement of patients in their care and possibly even an improvement in healthrelated quality of life.

The era of shared decision-making in healthcare is upon us, particularly regarding treatment modalities. It is considered as the apex of patient-centred care, allowing us to view healthcare experiences through the patient's eyes. ${ }^{32}$ According to the NHS, patients will be able to use "current, clinical information, relevant to their particular condition' and will be facilitated 'to work through any questions they may have, explore the options available, and take a treatment route which best suits their needs and expectations.' ${ }^{33}$ Thirty-eight patient 
decision aids are being created and uploaded to the Internet to include treatment options on such topics as depression, recurrent tonsillitis and smoking cessation. ${ }^{34}$ As highlighted by question 15 in DISCERN, websites should provide support for shared decision-making, however, only one website reviewed in this study provided this support. In a recent review by Stacey et al. the authors found that not only could shared decisionmaking empower patients in participating in their own healthcare but it could also help to address the problems such as over diagnosis and overtreatment. ${ }^{35}$ Although the NHS impetus for shared decision-making is proceeding in the medical field, a dearth of publications on this topic exist in the dental literature. ${ }^{36,37}$ Dental patients' attitudes to their involvement in treatment decisions has been reported as variable, ${ }^{38}$ however, we should still strive to engage those patients who are interested in becoming more involved in their own care.

\section{CONCLUSION}

A wide variety of types of information are available on the Internet regarding the treatment of oral ulcers with variable accuracy levels based on both JAMA benchmarks and DISCERN. Clinicians should provide guidance to patients regarding the scientific reliability of information and direction in filtering the information sourced.

1. Moses S. Family practice notebook. Family practice notebook, 2013. Online notebook available at http:/ www.fpnotebook.com/legacy/ (accessed August 2014)

2. Scully C, Shotts R. ABC of oral health. Mouth ulcers and other causes of orofacial soreness and pain. BMJ 2000; 321: 162-165.

3. Kovac-Kovacic M, Skaleric U. The prevalence of oral mucosal lesions in a population in Ljubljana Slovenia. J Oral Pathol Med 2000; 29: 331-335.

4. Zain R B. Oral recurrent aphthous ulcers/stomatitis: prevalence in Malaysia and an epidemiological update. J Oral Sci 2000; 42: 15-19.

5. Garcia-Pola Vallejo M J, Martinez Diaz-Canel A I, Garcia Martin J M, Gonzalez Garcia M. Risk factors for oral soft tissue lesions in an adult Spanish population. Community Dent Oral Epidemiol 2002; 30: 277-285.

6. Scully C, Gorsky M, Lozada-Nur F. The diagnosis and management of recurrent aphthous stomatitis: a consensus approach. J Am Dent Assoc 2003; 134: 200-207.

7. McMullan M. Patients using the Internet to obtain health information: how this affects the patienthealth professional relationship. Patient Educ Couns 2006; 63: 24-8.

8. Fox S, Raine L. The online health care revolution: how the web helps Americans take better care of themselves. Washington DC: Pew Charitable Trusts, 2000.

9. Nicholas D, Huntington P, Gunter B, Russell C, Whitney R. The British and their use of the web for health information and advice: a survey. Aslib Proc 2003; 55: 261-276.

10. Ziebland S, Chapple A, Dumelow C, Evans J, Prinjha $S$, Rozmovits L. How the internet affects patients' experience of cancer: a qualitative study. BMJ 2004; 328: 564

11. Bennett G G, Glasgow R E. The delivery of public health interventions via the Internet: actualizing their potential. Annu Rev Public Health 2009; 30: 273-292.

12. Eysenbach G, Powell J, Kuss O, Sa E R. Empirical studies assessing the quality of health information for consumers on the world wide web: a systematic review. JAMA 2002; 287: 2691-2700.

13. Ni Riordain R, McCreary C. Head and neck cancer information on the internet: type, accuracy and content. Oral Oncol 2009; 45: 675-677.

14. Park M W, Jo J H, Park J W. Quality and content of internet-based information on temporomandibular disorders. J Orofac Pain 2012; 26: 296-306.

15. Charnock D, Shepperd S, Needham G, Gann R. DISCERN: an instrument for judging the quality of written consumer health information on treatment choices. J Epidemiol Community Health 1999; 53: 105-111.

16. Silberg W M, Lundberg $G D$, Musacchio R A Assessing, controlling, and assuring the quality of medical information on the Internet: Caveant lecto et viewor-Let the reader and viewer beware. JAMA 1997: 277: 1244-1245.

17. Health on the Net Foundation. HONcode section for medical professionals. Online code available at http://www.hon.ch/HONcode/Pro/intro.html (accessed August 2014)

18. Mullen P D. Compliance becomes concordance. BMJ 1997; 314: 691-692.

19. Neelapala P, Duvvi S K, Kumar G, Kumar B N. Do gynaecology outpatients use the Internet to seek health information? A questionnaire survey. J Eval Clin Pract 2008; 14: 300-304.

20. Sacchetti $P, Z$ vara $P$, Plante M K. The Internet and patient education-resources and their reliability: focus on a select urologic topic. Urology 1999; 53: $1117-1120$.

21. Ayonrinde 0. Patients in cyberspace: information or confusion? Postgrad Med J 1998; 74: 449-450.
22. Eysenbach $\mathrm{G}$. The impact of the Internet on cancer outcomes. CA Cancer J Clin 2003; 53: 356-371.

23. Yahoo! UK and Ireland. What's the best cure for mouth ulcers? Yahoo! Answers, 2007.

24. The Health and Therapy Guide. Tips and advice for mouth ulcer relief. Online tips available at http:// www.gotosee.co.uk/healtharticles/2008/11/20-toptips-for-curing-mouth-ulcers/ (accessed August 2014).

25. Department for Business, Innovation and Skills. Engaging the public in science and engineering. London: Department for Business, Innovation and Skills, 2012.

26. National Literacy Trust. Literacy: state of the nation. National Literacy Trust, 2011.

27. Divaris $K$, Lee J Y, Baker A D, Vann W F Jr. The relationship of oral health literacy with oral healthrelated quality of life in a multi-racial sample of low-income female caregivers. Health Qual Life Outcomes 2011; 9: 108.

28. Lee J Y, Divaris K, Baker A D, Rozier R G, Vann W F $J r$. The relationship of oral health literacy and selfefficacy with oral health status and dental neglect. Am J Public Health 2012; 102: 923-929.

29. Trevena L J, Davey H M, Barratt A, Butow P, Caldwel P. A systematic review on communicating with patients about evidence. J Eval Clin Pract 2006; 12: 13-23.

30. Schapira M M, Meade C, Nattinger A B. Enhanced decision-making: the use of a videotape decisionaid for patients with prostate cancer. Patient Educ Couns 1997: 30: 119-127.

31. Ruffinengo $C$, Versino $E$, Renga $G$. Effectiveness of an informative video on reducing anxiety levels in patients undergoing elective coronarography: an RCT. Eur J Cardiovasc Nurs 2009; 8: 57-61.

32. Barry M J, Edgman-Levitan S. Shared decision making-pinnacle of patient-centreed care. N Engl J Med 2012; 366: 780-781.

33. Right Care. Shared decision making. Online information available at http://www.rightcare.nhs. uk/index.php/shared-decision-making/ (accessed August 2014).

34. Right Care. The patient decision aids. Online information available at http://www.rightcare.nhs. uk/index.php/shared-decision-making/about-thepdas/ (accessed August 2014).

35. Stacey D, Bennett C L, Barry M J et al. Decision aids for people facing health treatment or screening decisions. Cochrane Database Syst Rev 2011; CD001431.

36. Redford M, Gift H C. Dentist-patient interactions in treatment decision-making: a qualitative study. J Dent Educ 1997; 61: 16-21.

37. Oates A J, Fitzgerald M, Alexander G. Patient decision-making in relation to extensive restorative dental treatment. Part II: Evaluation of a patient decision-making model. Br Dent J 1995; 179: 11-18.

38. Chapple H, Shah S, Caress A L, Kay E J. Exploring dental patients' preferred roles in treatment decision-making- a novel approach. Br Dent J 2003; 194: $321-327$ 